\title{
Drifting-snow acoustic detector: experimental tests in La Molina, Spanish Pyrenees
}

\author{
D. Font, ${ }^{1}$ F. NaAim-Bouvet, ${ }^{2}$ M. Roussel ${ }^{2}$ \\ ${ }^{1}$ Departament de Geologia Dinàmica, Geofísica i Paleontología, Universitat de Barcelona, 08028 Barcelona, Spain \\ ${ }^{2}$ Division Nivologie, CEMAGREF, Domaine universitaire, BP 76, 38402 Saint-Martin-d'Hères Cedex, France
}

\begin{abstract}
A new gauge to detect drifting snow has been tested at an experimental site at La Molina, eastern Spanish Pyrenees during the 1996 winter.

Based on an acoustic principle, it consists of a miniature microphone located at the base of an aluminium pole of a variable length (depending on the average height of the snow accumulated in a season). While snowdrifting occurs and the pole is exposed to the flux (wind + snow particles), the snow grains impact on the pole and the sound produced by these collisions is recorded as an electrical signal.

$30 \mathrm{~m}$ away from the snowdrifting detector, there is an anemometric station. The comparison of both records allows determination of thresholds and deposit wind velocities. In addition, this gauge allows users to know, during a wind episode, the exact amount of time during which snowdrifting occurs without being in the field. The interpretation of the values obtained using the acoustic detector is not yet an easy subject to discuss. We still do not know what the drift-density equivalents for the recorded noise levels are. However, these are only preliminary results and we expect to complete the calibration of the gauge during the coming months.
\end{abstract}

\section{SAFETY AND SNOWDRIFTING}

Snowdrifting phenomena produce many problems to both managers of ski and mountain resorts and to the people in charge of the management of mountain roads and highways.

In the first case, snowdrifting produces snow cornices and slab accumulations that increase the avalanche hazard and entrainment of snow particles by wind produces erosion in exposed areas which implies important economic losses to managers of a ski resort.

The development of snowdrifts on roads and the lack of visibility occasioned by blowing snow impede driving and imply an increase in danger on the road network.

Since safety and access by the road network can be threatened by wind and snow-surface conditions, it is interesting to know in real time whether or not there is a snowdrifting event in some particular site.

\section{AEOLIAN TRANSPORT GAUGES}

\section{Mechanical collectors}

Research on snowdirifting phenomenon has been linked to the development of specific instruments. One of the principal aims has been determination of the drift flux (mass flux).

During the last 30 years, several gauges for studying snowdrifting have been developed. The first generation, in the $1960 \mathrm{~s}$, were mechanical particle traps. The mixture of air-snow particles passed through an inlet aperture and the air, without the particles, escaped through an outlet aperture. Retaining the particles from a flux was achieved by different methods: section enlarging, filtration, baffles and decantation. The mass of snow collected and the duration of the experiment all allow estimation of the drift flux (mass flux) at the inlet aperture level.

The simplest, and one of the first gauges to be used, was built using food tin cans fixed on a pole with an aperture facing the wind (Garcia, 1960). With this type of gauge some of the collected particles were expelled from the trap by wind-rebound effects. Over the years, improvements have been made in aerodynamic and particle-filtration efficiency.

Important improvements were achieved by Mellor (1965) (self-directional gauge), Bolognesi and others (1995) (multidirectional gauge) and Jairell (1975) (self-acting weighing system).

The last gauge, which automatically weighs the snow, avoids work in the field that is complicated but, on the other hand, does not allow the transmission of data in real time. These difficulties, especially for road-network managers, imply that mechanical traps have been little used outside the research context.

\section{Optical detector}

Throughout the 1980s, the second generation of snowdrifting traps was developed, based on optical and image-processing principles.

Initially, elaborated as research gauges, they are now operational in the U.S.A. (interstate 80 highway, Colorado; Martinelli and others, 1980) and in Japan (Hokkaido's highway; Takeuchi and others, 1990), because they allow the operators to investigate visibility conditions in real time (tied to snowdrifting phenomena) along the road. These safety devices are very complex and imply high economic investments. 


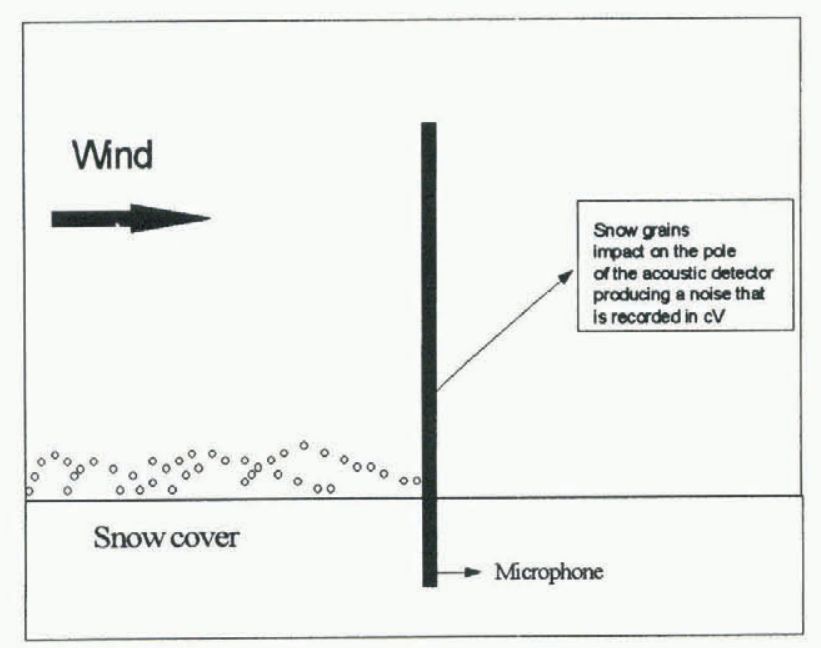

Fig. 1. Sketch of the acoustic transport detector.

\section{Acoustic detector}

In France, the "Division Nivologie", together with the AUTEG company from Grenoble, developed a snowdrifting detector (particle-transport detector). It is based on an acoustic principle and it consists of a miniature wide-band microphone placed at the base of an aluminium pole of variable length (according to the site's average thickness of seasonal snow cover) (Fig. 1). The pole is exposed to the snowdrifting flux. When snowdrifting occurs, the snow grains impact on the pole and the noise produced by these impacts is registered as an electrical signal by a sonometer that selects frequencies, by filtering the lower frequencies due to wind noise and the higher ones from the audible scale (Fig. 2). The signal is converted into a continuous tension value: the higher the kinetic energy of the impact of the particles, the greater the amplitude of the tension. Variation of the tensions is registered on a classical data logger.

During the winter 1996, this detector was tested at the ski resort of La Molina, in the Spanish eastern Pyrenees.

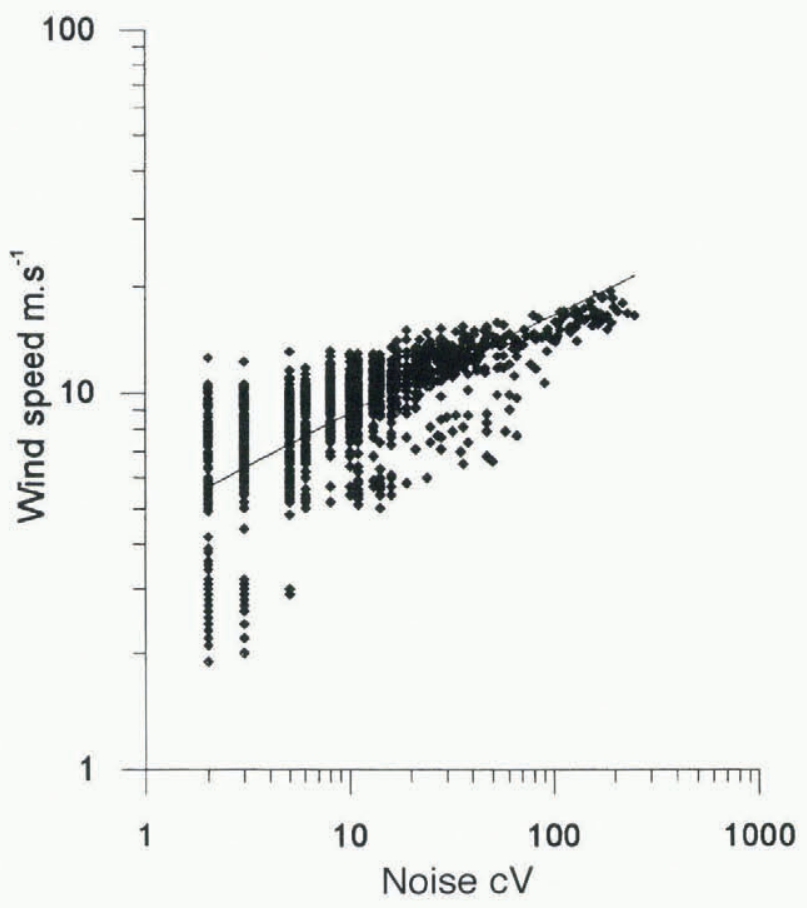

Fig. 2. Wind velocity vs noise (cV) for the 15 March 1996 snow-drifting episode.

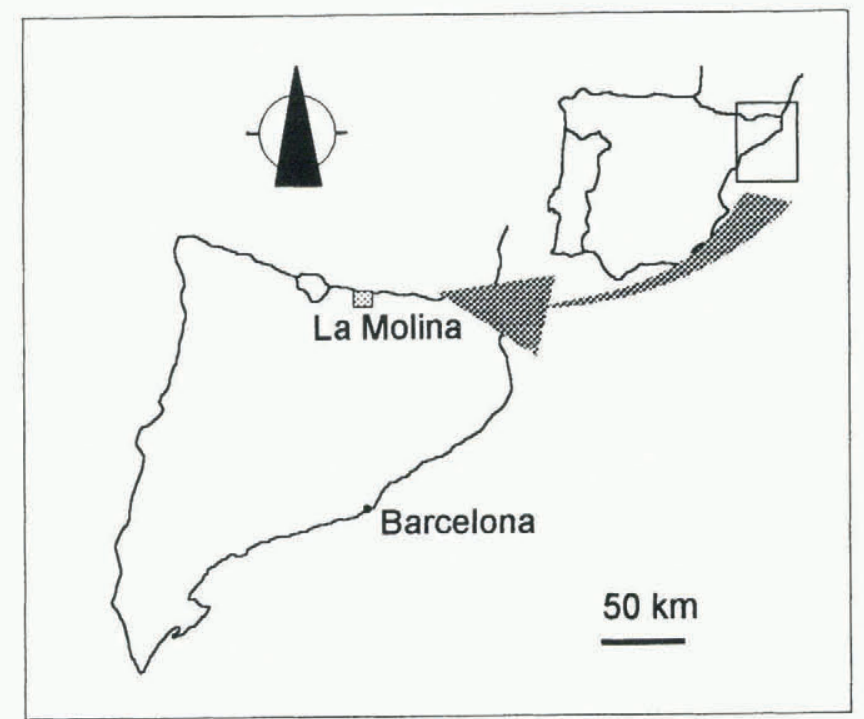

Fig. 3. Location of the experimental site at La Molina.

\section{THE EXPERIMENTAL SITE AT LA MOLINA}

Throughout the last 5 years, the Departament de Geologia Dinàmica, Geofisica i Paleontologia, University of Barcelona, has been working on snowdrifting phenomena at an experimental site at La Molina, eastern Pyrenees (Fig. 3).

It is a high planed area, at about $2350 \mathrm{~m}$ elevation, with a flat topography. Solid precipitation values are around $3 \mathrm{~m}$ at $2050 \mathrm{~m}$. Dominant winds are from the north, northwest and west and their maximum speed can reach $50 \mathrm{~m} \mathrm{~s}^{-1}$.

\section{Instrumentation}

Wind-vane and wind-speed sensor connected to a data logger Instrumentation consists of a wind-speed sensor, a wind vane, a battery and a data logger. The sensors are situated at $2300 \mathrm{~m}$, on a pylon of the Torrent Negre skilift (10 $\mathrm{m}$ high). The data logger and battery are located in a skilift hut and protected from the outside weather conditions. This anemometer station provides a continuous record throughout the snow season (approximately 7 months) of the average wind speed and wind direction, with a sampling time of 20 seconds and a logging time of 2 minutes.

\section{Snow-collector columns}

The snow is collected through a frontal opening of $6.15 \mathrm{~cm}^{2}$ and air escapes through a rear aperture of $12.5 \mathrm{~cm}^{2}$. Inside the boxes, there are three baffles that reduce the flux speed and reduce the deposition of the transported particles. The capacity of the collectors is $40 \mathrm{l}$. There are two different types of collector: one hand-built in fibreglass and the other manufactured in PVC. The outside dimensions and the inside volumes are exactly the same in both types. The main difference is the shape and situation of the inside baffles, which certainly affect the amount of snow collected and which governs the trapping efficiency of the gauge.

There are three columns of six boxes (collectors) each, two columns facing north (one in fibreglass and the other in PVC) and one facing northwest (fibreglass), as these are the two principal wind directions. The snow-collector columns remain fixed at the experimental site during the whole snow season. Systematically, once a week, the snow collectors are checked to verify the occurrence of snowdrift- 
ing. When there is evidence that snowdrifting has occurred, the collectors are emptied immediately. The collected snow is weighed and the data obtained give information on the vertical drift-density (concentration) profiles from 26 to $165 \mathrm{~cm}$ (Mases and others, 1996).

The snow-collector columns remain fixed at the experimental site; this means that they accumulate a representative part of the total amount of snowdrifted by the wind during the wind episode.

\section{Acoustic snowdrifting detector}

During 1995-96 season, the "Division Nivologie" and the University of Barcelona set up an acoustic snowdrift detector at the experimental site at La Molina.

The sensor is about $50 \mathrm{~m}$ from the anemometer, and the data logger, battery and solar panel used by the detector are installed in a ski-patrol equipment hut about $30 \mathrm{~m}$ from the detector.

\section{Snow traps}

The snow traps are nylon bags with a capacity of 21 and a frontal opening of $0.005 \mathrm{~m}^{2}$. The flux, constituted by wind plus snow grains, goes through the bag. Wind escapes through the nylon's porosity, leaving the snow in the bag. During these tests, we can use as many as ten bags, which means ten different heights. The bags are fixed between two aluminium poles. With the snow-trap column vertical, snowdrift density and mass-flux profiles are obtained. Simultaneously, to these measurements, vertical profiles of wind speed are recorded.

The snow traps were designed for short-duration tests during a snowdrifting episode, from 10 minutes to several hours, their lightness and mobility permit the operators to choose their location for each measurement.

Snow hardness, air- and snow-surface temperatures and humidities are other data recorded using the snow traps. To measure the snow hardness, a shear-strength device is used; it consists of a main part and three changeable crowns (of different diameters, according to the snow condition; Guily 1991).

During 1995-96 season, ten experiments were done, of which five were at $2070 \mathrm{~m}$ in the area of Costa Rasa and the other five at $2250 \mathrm{~m}$ at Solell's hut.

Data obtained with the snow traps coincide perfectly with the theoretical drift-density profiles (Fig. 4).

\section{EXPERIMENTAL RESULTS}

\section{The acoustic snowdrifting detector: a field gauge}

The incorporation of the acoustic snowdrifting detector at our experimental site is of great use. Without being in the field, we can determine with high accuracy when the snowdrifting event starts and when it finishes. The knowledge of the effective length of the drifting episode allows us to calculate the mass flux from the data obtained using the permanent ("in-situ") gauges. Knowledge of this length also allows us to calculate erosion velocities or the growth rates of snowdrifts or any kind of snow accumulation related to wind events (i.e. slabs and cornices).

The first field results using this acoustic detector to measure snowdrifting were obtained at La Molina during the months of March and April 1995-96 and during the 1996-97 season.

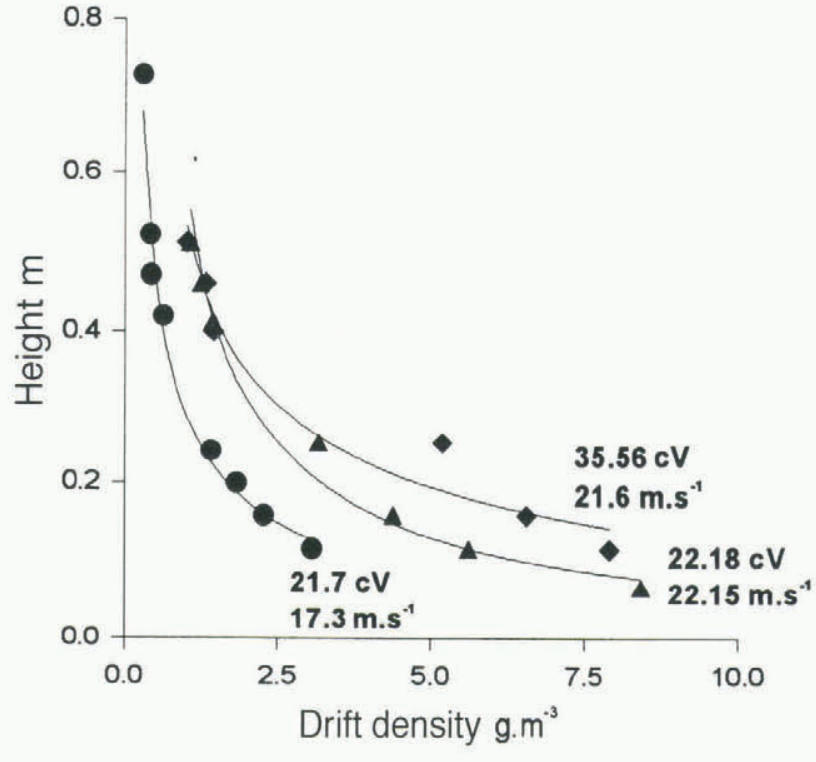

Fig. 4. Drift-density profiles shown beside the acoustic snowdrifting detector, average noise in cV and average wind velocity in $\mathrm{m}^{-1}$ are presented alongside each profile. Lines are fitted to the data.

If we compare wind-velocity data with the acoustic snowdrifting detector data, noise level in $\mathrm{cV}$, there is a proportional relationship between these two parameters (Fig. 2).

At this point, we considered it necessary to establish a relation between the data obtained using the acoustic detector: noise $(\mathrm{cV})$ and wind velocity $\left(\mathrm{m} \mathrm{s}^{-1}\right)$ and the natural phenomenon itself. We intended characterizing the snowdrifting episode using the acoustic detector data. It seemed necessary to compare the signal obtained using the acoustic detector directly to the drift flux or to the drift density of snow particles in order to improve the information obtained. Actually, we could only affirm whether there was no drifting, weak drifting, medium drifting, important drifting or very important drifting. Some field tests have been made of snowdrifting events where the acoustic detector records drift density and snow traps are also used at the same place. The results were compared in order to calibrate the acoustic snowdrifting detector.

In Figure 4, three drift-density profiles are presented, which belong to the 15 February 1997 snowdrifting event. Each profile has its average noise in $\mathrm{cV}$ and average wind velocity in $\mathrm{ms}^{-1}$. The average noise produced by blowing snow particles increases with drift-density values. Wind velocity is also proportional to the recorded noise. However, there are some exceptions. The profile that presents higher drift-density values has a lower wind-velocity value than the second one. We consider that this is due to changes in the snow-surface condition, while the snowdrifting event occurred.

If the acoustic transport detector is used in an environment where the particles in motion are not affected by temperature and humidity variations (i.e. sand), the calibration can be done in a wind tunnel, using an image-processing system as a complementary device.

In snowdrifting, calibration should be done in a cold wind tunnel for the different types of snow grain or "in situ", because, evidently, the type of snow grain will influence the noise level. 


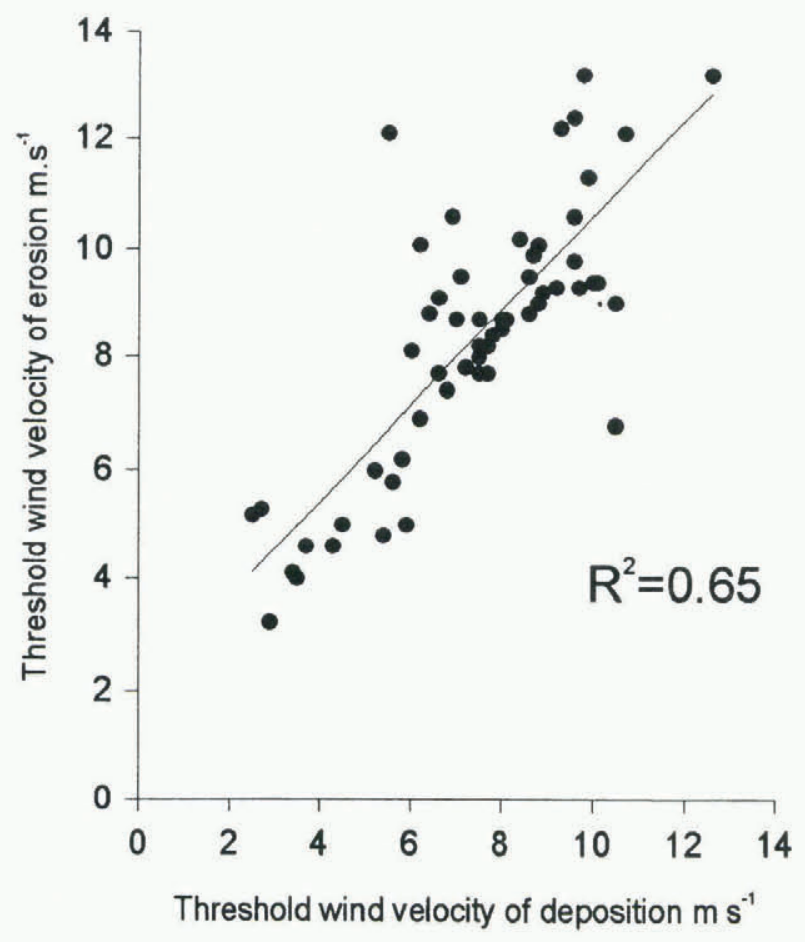

Fig. 5. Relationship between the threshold wind velocity of erosion and the threshold wind velocity of deposition from the field data obtained during the 15-16 March, 1 and 4 April 1996 at La Molina.

The acoustic snowdrifting detector: a research gauge

Despite the failure to understand quantitatively the correlation between the level of noise and the drift density, this detector already constitutes an interesting gauge in the aeolian-transport research domain.

For example, the relationship between the threshold wind velocity of erosion (wind velocity when the drifting starts, threshold drag wind velocity) and the threshold wind velocity of deposition (wind velocity when the drifting stops) has been established. The relationship between the threshold wind velocities is similar to that established by Bagnold (1941) for sand. Even if a proportional relationship is observed between the two threshold wind velocities (erosion and deposition), the threshold wind velocities of erosion are higher than the threshold wind velocities of deposition. It is also interesting to note that, for different wind episodes, the threshold wind velocities of erosion and deposition range from 3 to $13 \mathrm{~m} \mathrm{~s}^{-1}$ (Fig. 5). This wide range of wind velocities is probably caused by the different conditions of snow surface; the stronger the inter-grain cohesion in the snow surface, the higher the threshold wind velocity of erosion.

\section{CONGLUSIONS}

In any kind of aeolian research, the acoustic transport detector would be an interesting gauge to use. We have established its usefulness in research concerning snowdrifting.

Knowledge of the effective duration of snowdrifting in a wind episode is an important parameter that complements all the other measurements done in snowdrifting research.

The first field results obtained are very encouraging. There is a proportional relationship between wind velocity and the sound recorded with the acoustic detector. Then, we oi.org/10.3189/1 998AoG26-1-221-224 Published online by Cambridge University Press assume a proportional relationship between noise and driftdensity values.

The relationship found between the threshold wind velocity of erosion and the threshold wind velocity of deposition has been established from the acoustic detector data. This relationship, between the two threshold wind velocities, is similar to that established by Bagnold (1941) for sands. It is also remarkable that threshold wind velocities of erosion and deposition range from 3 to $13 \mathrm{~m} \mathrm{~s}^{-1}$. We consider that this wide range of wind velocities is due to the different conditions of the snow surface.

The interpretation of the values obtained using the acoustic detector is not easy. We do not yet know the driftdensity equivalents for the noise levels. A sound of $50 \mathrm{cV}$ can be produced by many small impacts or by a few highenergy impacts. We expect to improve the research along this line and to obtain sufficient field information during the following seasons in order to understand better the behaviour of this transport detector.

\section{ACKNOWLEDGEMENTS}

This research was funded by Project AMB-0837 from the CICYT and the Project of Human Capital and Mobility of the ECC, contract No. CHRX-CT93-0307 (DG COMA). Thanks are due to J. M. Vilaplana for his support during the research.

Thanks are also due to F. Gallart and his team, from the Institute of Earth Sciences "Jaume Almera" in Barcelona, for support and advice given during management of the field equipment. The authors thank K. Nishimura, P. Gauer and an anonymous reviewer for critically reviewing earlierversions of the manuscript. Their comments were insightful and informative.

We should also like to thank those responsible for the logistical support given by La Molina (Ferrocarrils de la Generalitat de Catalunya) ski resort and especially the skipatrol team.

Finally we should like to acknowledge the Auteg company of Grenoble which was in charge of manufacturing the acoustic transport detector.

\section{REFERENCES}

Bagnold, R.A. 1941. The physics of blowing sand and desert dunes. London, Methuen.

Bolognesi, R., J. -M. Daultier, F. Naaim-Bouvet and F. Ousset. 1995. Une évaluation quantitative du snowdrift pour la prévision locale des avalanches. Neiges et Avalanches 69, 2-7.

Garcia, R. 1960. Mesures du transport de neige par le vent à la station Charcot. Météorologie, 57(4), 205-212.

Guily, L. 1991. L'exploitation technique des pistes de ski alpin dans le domaine skiable français. (Thèse de doctorat d'état, Université Joseph Fourier-Grenoble I.)

Jairell, R. L. 1975. An improved recording gage for blowing snow. Water Resour. Res., 11(5), 674-680.

Martinelli, M., Jr, R. Schmidt and R. Tabler. 1981. Research application helps solve blowing snow problems. Fort Collins, CO, U.S. Department of Agriculture. Forest Service. Rocky Mountain Forest and Range Experiment Station.

Mases, M., H. Martinez, J.M. Vilaplana and D. Font. 1996. Medidas de transporte de nieve por el viento en el Pirineo oriental catalan. Geogaceta, 20 (5), 1107-1108.

Mellor, M. 1965. Blowing snow. CRREL Monogr. III-A3c.

Takeuchi, M., K. Ishimoto and Y. Kajiya. 1990. Blowing snow problems and their countermeasures in Hokkaido, Japan. In Eighth PIARC International Winter Road Congress. Proceedings. Vol. II. Sapporo, Japan, Hokkaido Development Bureau. Civil Engineering Research Institute, 249-26l. 